\title{
Conhecimento local sobre cactáceas em comunidades rurais na mesorregião do sertão da Paraíba (Nordeste, Brasil)
}

\author{
Camilla Marques de Lucena ${ }^{1}$ \\ Gabriela Maciel da Costa ${ }^{1}$ \\ Rodrigo Ferreira de Sousa ${ }^{1}$ \\ Thamires Kelly Nunes Carvalho ${ }^{1}$ \\ Nayze de Almeida Marreiros ${ }^{1}$ \\ Carlos Antônio Belarmino Alves ${ }^{2}$ \\ Daniel Duarte Pereira ${ }^{1}$ \\ Reinaldo Farias Paiva de Lucena ${ }^{1 *}$ \\ ${ }^{1}$ Universidade Federal da Paraíba, Campus II, Centro de Ciências Agrárias \\ Departamento de Fitotecnia e Ciências Ambientais, Laboratório de Etnoecologia \\ CEP 58.397-000, Areia -PB, Brasil \\ ${ }^{2}$ Universidade Estadual da Paraíba, Campus III, Centro de Humanidade \\ Departamento de Geografia e História, Guarabira - PB, Brasil \\ * Autor para correspondência \\ reinaldo@cca.ufpb.br
}

Submetido em 30/08/2011

Aceito para publicação em 12/04/2012

\section{Resumo}

O presente estudo objetivou registrar o conhecimento e uso que os moradores das comunidades rurais de Besouro e Barroquinha no município de Lagoa (Paraíba, Brasil) possuem em relação as cactáceas. Foram realizadas entrevistas semiestruturadas com 38 informantes (14 homens e 24 mulheres) em Barroquinha e 14 em Besouro (cinco homens e nove mulheres). Os cactos citados foram organizados em categorias de uso. Identificaram-se cinco espécies nas duas comunidades: Cereus jamacaru DC., Melocactus sp., Pilosocereus chrysostele (Vaupel) Byles \& G. D. Rowley, Nopalea cochenillifera (L.) Salm-Dyck e Pilosocereus gounellei (F.A.C. Weber) Byles \& G. D. Rowley. Registraram-se 201 citações de uso em Barroquinha, organizadas em sete categorias e 76 citações em Besouro, organizadas em oito categorias. Em ambas as comunidades, o C.jamacaru foi mais citado e, quanto à categoria, a forragem foi a que obteve maior relevância nas duas comunidades. $\mathrm{O}$ conhecimento sobre as cactáceas mostrou-se semelhante em relação ao sexo dos informantes. Com relação à disseminação do conhecimento, foi constatado o predomínio da transmissão vertical, ou seja, de pais para filhos. As potencialidades de uso das cactáceas nas comunidades Besouro e Barroquinha demonstram sua importância local, devido aos vários usos e categorias aplicadas as espécies.

Palavras-chave: Cactos; Etnobotânica; Transmissão de conhecimento 


\section{Abstract}

Local knowledge about cacti in rural communities in the mesoregion of Paraíba State (Northeastern Brazil). The goal of this study was to record the uses and knowledge of cacti in the rural communities of Barroquinha and Besouro, in the municipality of Lagoa, in Paraíba, Brazil. Semi-structured interviews were conducted with 52 informants (men and women). The cacti cited were organized into eight categories of use. Five species were identified in the communities: Cereus jamacaru DC., Melocactus sp., Pilosocereus chrysostele (Vaupel) Byles \& G. D. Rowley, Nopalea cochenillifera (L.) Salm-Dyck and Pilosocereus gounellei (F.A.C. Weber) Byles \& Rowley. We registered 201 citations of use in Barroquinha, which were placed in seven categories, and 76 citations in Besouro, which were placed in eight categories. In both communities, C. jamacaru was the most used specie and forage was the most common category of use. Within the communities, the men and women had similar knowledge about these plants. In relation to the transmission of knowledge, there was a predominance of a vertical transmission, from parents to children. Based on the categories applied to the species, the various uses recorded show that these cacti are important to the Besouro and Barroquinha communities.

Key words: Cacti; Ethnobotany; Transmission of knowledge

\section{Introdução}

A Paraíba apresenta três regiões climáticas, sendo elas o Sertão, situado na faixa semiárida, o Planalto da Borborema e a Fachada Atlântica Tropical (ALVES, 2009). Dessas regiões, foi escolhida para a realização do presente estudo, a mesorregião do sertão paraibano a qual faz limite com a mesorregião Seridó. O sertão apresenta uma vegetação adaptada aos baixos índices pluviométricos e diferentes estruturas vegetacionais. Suas áreas são dominadas tanto por espécies de porte árboreo, formando matas abertas, como por espécies de porte herbáceo/arbustivo, significativamente representadas por espécies da família Cactaceae, adaptadas à altas temperaturas e ao clima seco (DUQUE, 2004).

Em virtude das poucas espécies de cactos presentes nas áreas de mata encontradas no sertão, raras em alguns ambientes, bem como da constante ação antrópica e do processo de desertificação, aspectos que ameaçam a biodiversidade no semiárido nordestino (DUQUE, 2004), torna-se necessário o desenvolvimento de estudos que registrem o conhecimento das populações locais sobre tais espécies e o uso que se faz delas. Tal registro mostrase de grande importância na elaboração de estratégias eficazes de conservação das espécies ameaçadas localmente, especialmente quando se considera o envolvimento das populações locais nesse processo. Nesse sentido, a perspectiva da Etnobotânica mostrase eficaz, pois procura entender a dinâmica da relação das pessoas viventes com os recursos vegetais (ALBUQUERQUE; ANDRADE, 2002).

Poucos são os estudos etnobotânicos desenvolvidos no Brasil envolvendo o conhecimento local sobre cactáceas (ANDRADE et al., 2006a; 2006b; LUCENA, 2011). Em contrapartida, em outros países do continente americano essa temática vem sendo bem documentada, principalmente no México (APODACA, 2001; LUNAMORALES; AGUIRRE, 2001; CRUZ; CASAS, 2002; ARELLANO; CASAS, 2003; CARMONA; CASAS, 2005; FUENTES, 2005; NILSEN et al., 2005; CASAS et al., 2006; FERNÁNDEZ-ALONSO, 2006; JIMÉNEZSIERRA; EGUIARTE, 2010).

As cactáceas apresentam grande importância regional, principalmente pelo fato das mesmas serem utilizadas na alimentação animal, sendo seu uso requisitado, principalmente, em épocas de seca, quando a carência de plantas alimentícias é maior (DUQUE, 1980; PEREIRA, 2009). Além disso, os cactos também são utilizados na medicina local, e em construções rurais e domésticas, como registrado em outras áreas de caatinga (LIMA, 1996; PEDROSA, 2000; ANDRADE et al., 2006a; PEREIRA, 2009; LUCENA, 2011).

Diante do exposto o presente estudo buscou registrar o conhecimento e uso que os moradores das comunidades rurais Besouro e Barroquinha no município de Lagoa (Paraíba, Brasil), fazem das cactáceas presentes em sua região. 


\section{Material e Métodos}

\section{Área de estudo}

O estudo foi realizado nas comunidades rurais Besouro e Barroquinha, no município de Lagoa, estado da Paraíba, Nordeste do Brasil, situado na mesorregião do Sertão e microrregião de Catolé do Rocha, distante $394 \mathrm{~km}$ da capital do Estado. Sua população de 4.681 habitantes (2.377 na zona rural e 2.304 na zona urbana) encontra-se distribuída numa área de $177,901 \mathrm{~km}^{2}$ que tem como municípios limítrofes de Bom Sucesso, Jericó e Mato Grosso (ao norte), Pombal (ao sul), Paulista (ao leste) e Santa Cruz (ao oeste) (IBGE, 2010). Algumas comunidades rurais têm destaque no município, como Jatobá, Timbauba, Jutubarana e Barroquinha, as quais são consideradas as maiores em termos de população residente. Algumas serras estão presentes em torno das comunidades, sendo em Barroquinha as serras de Claudiano, Zé Rodrigues e Balanço, já em Besouro a serra Peru e parte da serra de Zé Rodrigues. A altitude média dessas serras é de cerca de $500 \mathrm{~m}$.

A Bacia Hidrográfica do médio Piranhas é o principal curso de água de Lagoa, o qual auxilia na criação do gado e na manutenção das lavouras. O clima é semiárido quente, com temperatura média de $27^{\circ} \mathrm{C}$, com um período de estiagem que pode atingir até 11 meses (IBGE, 2010).

A economia está voltada para agropecuária com a criação de ovinos, caprinos e bovinos, e para a cultura de feijão, fumo, algodão e milho.

\section{Coleta de dados etnobotânicos}

Os dados etnobotânicos foram coletados no mês de julho de 2011, sendo visitadas $100 \%$ das residências habitadas da comunidade Barroquinha (42 casas) e da comunidade Besouro (nove casas). Em Barroquinha participaram 38 informantes (14 homens e 24 mulheres) correspondendo a 24 casas ( $57 \%$ das residências), pois as pessoas de 18 residências se negaram a participar. Em Besouro participaram 14 informantes (cinco homens e nove mulheres), representando $100 \%$ das residências. Houve uma diferença entre o número de homens e mulheres abordado devido à presença de viúvas e solteiras, e por algumas pessoas não terem sido encontradas no momento da visita.

Foram entrevistados os chefes domiciliares, homens e mulheres, com os quais aplicaram-se entrevistas semiestruturadas, em momentos distintos (ALBUQUERQUE et al., 2010). Antes das entrevistas, uma conversa foi realizada explicando o objetivo do trabalho, momento no qual os mesmos foram convidados a assinar o Termo de Consentimento Livre e Esclarecido, exigido pelo Conselho Nacional de Saúde por meio do Comitê de Ética em Pesquisa (Resolução 196/96). O presente estudo foi aprovado pelo Comitê de Ética em Pesquisa com Seres Humanos (CEP) do Hospital Lauro Wanderley da Universidade Federal da Paraíba, em sessão realizada no dia 26 de abril de 2011, registrado com protocolo CEP/HULW no $297 / 11$, com folha de rosto $\mathrm{n}^{\mathrm{o}} 420134$.

As comunidades rurais Barroquinha e Besouro são adjacentes, sendo a primeira mais próxima da sede do município de Lagoa (cerca de $1 \mathrm{~km}$ ) e a segunda distando cerca de $2 \mathrm{~km}$ da sede. A maior parte dos informantes das comunidades são agricultores (47\%). No entanto, outras ocupações podem ser registradas como, costureiras, donas de casa, empregadas domésticas, funcionários públicos, motoristas, professores e vigilantes. Alguns dos moradores tiram seu sustento da aposentadoria. As crianças de ambas comunidades estudam em escolas públicas na cidade, devido a ausência das mesmas nas comunidades.

As entrevistas continham perguntas relacionadas ao conhecimento e uso das cactáceas. Os cactos citados foram organizados em categorias de uso, estabelecidas pelos pesquisadores com o auxílio de material bibliográfico (ANDRADE et al., 2006a; LUCENA, 2011) sendo elas: alimentação, construção, forragem (alimento animal), mágico religioso, medicinal, ornamental, sombra e tecnologia. Os espécimes coletados foram herborizados em campo, sendo incorporados no Herbário Jaime Coêlho de Moraes (EAN) da Universidade Federal da Paraíba, no Centro de Ciências Agrárias (CCA). 


\section{Resultados}

\section{Características socioeconômicas dos entrevistados}

Em Barroquinha, a maioria dos informantes são agricultores ativos (48\%). Destaque também para as donas de casa (37\%) e funcionários públicos $(15 \%)$. Já a renda predominante é oriunda da bolsa de agricultor (seguro safra) (32\% dos informantes), seguida da aposentadoria (29\%) e bolsa família (9\%). O restante dos informantes tira seu sustento de atividades diversas, como empregada doméstica (1\%) e diaristas e funcionários públicos $(29 \%)$.

Em Besouro, 50\% das entrevistadas são donas de casa, $37 \%$ agricultores, $10 \%$ aposentados e $3 \%$ dedicam-se a outras atividades (costureira). A renda é predominantemente obtida através da aposentadoria $(60 \%)$, seguida da agricultura (16\%) e de benefícios do governo, como o bolsa família (16\%). Alguns informantes não quiseram mencionar o valor de sua renda mensal $(8 \%)$.

Com relação ao estado civil, em Barroquinha a maioria dos entrevistados é casado(a) (92,50\%), seguida pelos viúvos(as) $(4,50 \%)$ e solteiros(as) (3\%). Já em Besouro, todos os informantes são casados (100\%). No tocante à escolaridade, constatou-se que $46 \%$ dos entrevistados em Barroquinha cursou o primeiro grau, concluído por $8 \%$ deles, $33 \%$ são analfabetos e $17 \%$ cursou até o segundo grau. Quatro porcento declarou saber apenas ler. Em Besouro, 33\% deles são analfabetos, $39 \%$ cursaram até o primeiro grau, concluído por $8 \%$ deles, e $4 \%$ estudaram até o segundo grau. Vinte e quatro porcento dos entrevistados nesta localidade afirmou apenas saber ler.

Com relação ao número de residentes por domicílio, verificou-se uma média de quatro pessoas, em ambas comunidades.

\section{Aspectos etnobotânicos dos cactos}

Registrou-se o uso de cinco espécies nas duas comunidades, sendo elas Cereus jamacaru DC. (mandacaru), Melocactus sp. (coroa de frade),
Pilosocereus chrysostele (Vaupel) Byles \& G. D. Rowley (facheiro), Nopalea cochenillifera (L.) Salm-Dyck (palma doce) e Pilosocereus gounellei (F.A.C. Weber) Byles \& G. D. Rowley (xiquexique), pertencentes a quatro gêneros.

$\mathrm{Na}$ comunidade Barroquinha foram registradas 201 citações de uso, 120 feitas por mulheres e 81 por homens. As espécies foram organizadas, de acordo com as citações, em sete categorias de uso (alimentação, forragem, mágico religioso, medicinal, ornamental, sombra e tecnologia). Em Besouro, obtiveram-se 76 citações de uso, das quais 44 foram feitas por mulheres e 32 por homens. Assim como em Barroquinha, em Besouro as espécies foram organizadas, de acordo com as citações, em oito categorias de uso, sendo acrescentada a categoria construção, a qual não foi registrada em Barroquinha (Tabela 1). Em ambas as comunidades, as espécies foram mencionadas como úteis para mais de uma finalidade de uso, sendo, portanto, espécies versáteis.

Em Barroquinha, as espécies mais citadas foram $C$. jamacaru, P. gounellei e N. cochenillifera. Em Besouro as espécies mais citadas também foram $C$. jamacaru, $N$. cochenillifera e $P$. gounellei (Tabela 2).

Em ambas as comunidades, as categorias de uso que mais se destacaram foram: forragem (81 citações em Barroquinha e 35 em Besouro), alimento (39 em Barroquinha e 16 em Besouro) e medicinal (33 em Barroquinha e dez em Besouro).

Quanto à versatilidade de uso, as espécies que mais se destacaram foram C. jamacaru em Barroquinha, sendo registrada em oito categorias de uso, e $P$. gounellei em Besouro em seis categorias.

Com relação às partes usadas das plantas, constatouse que $C$. jamacaru foi a espécie com maior número delas, em ambas as comunidades (cinco partes úteis em Barroquinha e seis em Besouro). De forma geral, a planta é mais usada inteira (74 citações desse modo de uso em Barroquinha e 25 em Besouro), principalmente quando destinada à alimentação de animais (categoria forragem).

Para a espécie Melocactus sp., registrou-se o uso do "miolo" (parênquima aquífero), na categoria alimento humano, para o preparo de doces e na categoria medicinal, 
para o preparo de expectorantes (feito pela mistura do parênquima aquífero com açúcar). Para o tratamento de problemas renais, é retirada a parte superior (tricomas) do vegetal, a qual é inserida em água dentro do cladódio para, no dia seguinte, ser consumida. Tal espécie também é utilizada para forragem, quando queimada "inteira" ou para uso mágico religioso e ornamental.

Pilosocereus chrysostele tem seu fruto consumido em fresco pelos entrevistados e pode ainda ser usada inteira, queimada, para forragem ou em jardins para ornamentação.

Cereus jamacaru também é usada na alimentação humana, quando têm seu fruto consumido em fresco. No uso forrageiro, é usada inteira e queimada. O fruto também é consumido pelos pássaros. Além disso, essa espécie é ainda utilizada em práticas mágicas religiosas, como sombra e ornamentação nas residências. Para finalidades medicinais, utiliza-se sua raiz para elaboração do chá por meio da decocção, ou por molho (coloca a raiz de molho na água), quando empregado no combate de problemas de colesterol, coração, gastrite, gripe e infecção. Seu miolo também é usado, do qual se retiram três "rodelas" sem sua epiderme, as quais são colocadas na água. Tal preparo deve ser consumido no dia seguinte, quando se objetiva tratar de enfermidades como "infecção da mulher", gastrite, ferida no útero, rins, úlcera e inflamação. No uso construção, C. jamacaru tem seu indivíduo inteiro usado para a confecção de cercas-vivas e, para tecnologia, utiliza-se a raiz para o manufaturamento de colheres-de-pau na comunidade de Barroquinha, já na comunidade de Besouro é utilizada a madeira para o mesmo fim.

Além de todos os usos acima registrados, $C$. jamacaru também foi citado em ambas comunidades como bioindicador de chuva (11 citações em Barroquinha e sete em Besouro). Apesar do registro dessa utilização, a mesma não foi colocada como categoria de uso no presente estudo.
Nopalea cochenillifera tem seu fruto consumido em fresco, como alimento humano, e para forragem, podendo ser utilizada em associação com rações convencionais. A planta inteira pode ainda servir para os usos mágico religioso, sombra e ornamental.

Pilosocereus gounellei tem seu miolo (medula) cozido ou seu fruto consumido em fresco, na alimentação humana. Para forrageio, a planta inteira é queimada e usada para alimentar animais, ou seu fruto é consumido em fresco pelos pássaros. Para uso medicinal, o miolo é colocado de molho na água para tratar enfermidades como gastrite. Na categoria tecnologia, o espinho é usado como agulha, na confecção de renda de almofada. Nas categorias mágico religioso, sombra e ornamental a planta é usada inteira.

Tanto em Barroquinha como em Besouro, os resultados foram semelhantes quando comparadas às informações coletadas entre homens e mulheres, pois categorias como forragem, alimento e medicinal foram as mais proeminentes para ambos os grupos.

Em ambas as comunidades a maioria dos informantes mostrou ter adquirido o conhecimento de forma vertical, com os avôs e pais (Barroquinha: 74\%; Besouro: 67\%). O restante deles $(26,14 \%)$ adquiriu o conhecimento de forma circular, com os amigos ou vizinhos na comunidade (Barroquinha: 26\%; Besouro: $33 \%)$.

A maioria dos informantes, em ambas as localidades, afirmaram não transmitir o conhecimento que possuem sobre plantas para filhos, amigos ou parentes (Besouro: 45\%; Barroquinha: 57\%). Um total de $40,80 \%$ dos entrevistados em Besouro e 30,84\% Barroquinha afirmaram transmiti-lo de forma circular e $14,47 \%$ em Besouro e 12,44\% em Barroquinha de forma vertical. 
TABELA 1: Categorias de uso das espécies de cactáceas citadas pelos moradores das comunidades rurais Barroquinha e Besouro em Lagoa-PB (Nordeste do Brasil).

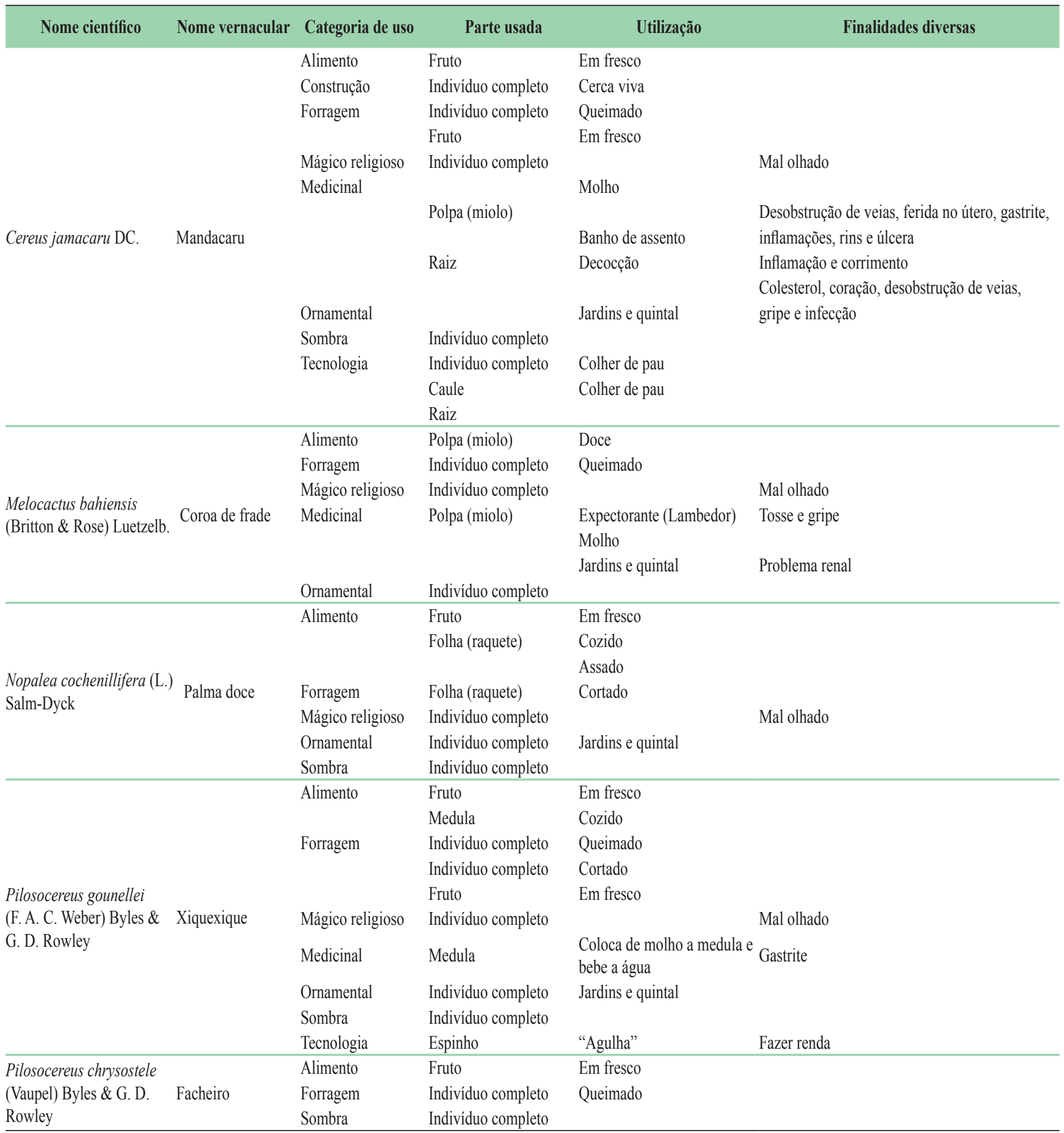


TABELA 2: Espécies de cactáceas citadas pelos moradores das comunidades rurais Barroquinha e Besouro em Lagoa-PB (Nordeste do Brasil), com suas respectivas citações de uso e porcentagem geral.

\begin{tabular}{lcccc}
\hline \multicolumn{1}{c}{ Espécie } & Barroquinhas & Besouro & Barroquinhas & Besouro \\
\cline { 2 - 5 } & \multicolumn{2}{c}{ Citação de uso } & Porcentagem geral \\
\hline Cereus jamacaru DC. & 96 & 35 & 48 & 46 \\
Pilosocereus gounellei (F. A. C. Weber) Byles \& G. D. Rowley & 46 & 16 & 23 & 21 \\
Nopalea cochenillifera (L.) Salm-Dyck & 36 & 17 & 18 & 22 \\
Pilosocereus chrysostele (Vaupel) Byles \& G. D. Rowley & 6 & 5 & 3 & 7 \\
Melocactus sp. & 17 & 3 & 8 & 4 \\
\hline
\end{tabular}

\section{Discussão}

\section{Diversidade biológica e cultural de cactáceas}

A diversidade de espécies e de usos registrados para a família Cactaceae nas comunidades de Barroquinha e Besouro foram baixos, em relação ao encontrado em outras comunidades no Nordeste do Brasil (ANDRADE et al., 2006a; 2006b; LUCENA, 2011). Andrade et al. (2006a) e Lucena (2011) registraram número maior de espécies dessa família sendo usadas por comunidades do sertão baiano e cariri paraibano (dez e nove, respectivamente). Além disso, ambos autores registraram maior diversidade de uso das cactáceas nas comunidades rurais mencionadas. Essa situação pode ser reflexo da existência de poucas espécies de cactos na região do sertão nordestino, como afirma Duque (2004).

As categorias de uso "forragem" e "alimento humano" obtiveram destaque nas duas comunidades, tendência também constatada por Lucena (2011), ao estudar a comunidade de São Francisco, no município de Cabaceiras, Paraíba. Apesar da categoria "alimento humano" ter sido a segunda mais citada nas duas comunidades, por meio dos depoimentos, percebe-se que o uso de algumas espécies de cactos para esta finalidade atualmente não se configura um uso real, mas sim cognitivo, conforme consta abaixo:

"Antigamente, em 1942, usava mais o xiquexique e o mandacaru, o povo escapava na alimentação"

(R. A. S., 54 anos).

"Quando havia ano de seca usava mais" (A.S., 69 anos).
O consumo pretérito das cactáceas na região estudada foi influenciado pela ocorrência de um expressivo período de seca na região, no ano de 1942, durante o qual muitos moradores no município de Lagoa sobreviveram se alimentando de espécies como $P$. gounellei e $N$. cochenillifera. Atualmente acredita-se que o abandono do uso dessas espécies como alimento também pode ser atribuído ao acesso das famílias locais aos programas de auxílio do governo, como bolsa família e bolsa escola, conforme mencionado por Cavalcanti Filho (2010) e Lucena (2011), no município de Cabaceiras.

A categoria "forragem", a mais expressiva em ambas as comunidades, também se mostrou importante em outras localidades de diferentes regiões do Brasil (ANDRADE et al., 2006a; CAVALCANTI FILHO, 2010; LUCENA, 2011). As espécies mais citadas nesta categoria de uso foram C. jamacaru, P. gounellei e a $N$. cochenillifera nas duas comunidades, ao contrário do encontrado por Lucena (2011) ao estudar comunidades da região do cariri, situada no Planalto da Borborema. Nesse estudo, o autor afirma que Opuntia ficus indica é a espécie que mais se destaca na categoria de uso em questão. A predominância de $O$. ficus indica no Cariri pode ser explicado pelas condições ambientais da região, onde se registra maior umidade relativa do ar, favorecendo sua ocorrência, bem como a de outras espécies também influenciadas por fatores como altitude e índice pluviométrico.

Na categoria "construção", apenas $C$. jamacaru foi citada como usada, na comunidade Besouro, onde é empregada como "cerca viva". Essa finalidade de uso é também registrada em outros estudos, apesar de atribuída a espécies diferentes como C. hexagonous e $N$. 
cochenillifera, nas regiões secas de Cuba (FUENTES, 2005), e $P$. gounellei na região semi-árida do cariri paraibano (LUCENA, 2011).

A categoria "medicinal" foi a terceira mais citada no presente estudo sendo as espécies Melocactus sp. e C. jamacaru as mais usadas. Assim como encontrado no presente, o uso medicinal também é evidenciado em outros estudos (ANDRADE et al., 2006b; DANTAS; GUIMARÃES, 2007; CHAVES et al., 2008; DANTAS et al., 2008; OLIVEIRA et al., 2010; ROQUE et al., 2010; LUCENA, 2011). O uso do miolo (parênquima aquífero) de Melocactus sp. no preparo de remédios caseiros foi registrado tanto por Andrade et al. (2006b), entre sertanejos baianos, no tratamento de problemas no intestino e cólicas, como por Lucena (2011), no Cariri Paraibano, no combate da coqueluche e verme.

A espécie C. jamacaru (mandacaru), a mais citada no presente estudo, foi também registrada como importante por Andrade et al. (2006a), ao estudarem comunidades do Sertão Baiano, onde seu fruto é usado como alimento humano. No uso tecnológico, as comunidades de Barroquinha e Besouro utilizam a raiz para fabricação de colher de pau. Duque (2004) relata que na categoria de uso "forrageio", geralmente o C. jamacaru é servido ao gado bovino depois que os espinhos são queimados. Já o fruto é bastante consumido pelos pássaros, corroborando com Cavalcanti e Resende (2007). Esta mesma espécie recebeu significativa citação na categoria medicinal. Na comunidade de Besouro foi mencionada no tratamento de quatro tipos de doenças (corrimento, gastrite, infecção e inflamação) e, em Barroquinha, é empregada para tratar onze enfermidades (colesterol, coração, desobstrução de veias, ferida no útero, gastrite, gripe, inflamação, inflamação da genitália feminina, problema renal, tosse e úlcera). Andrade et al. (2006b), ao estudarem sertanejos do estado da Bahia, também relatam o uso da raiz dessa espécie para tratar algumas enfermidades como a gripe, problema nos rins e sífilis. Lucena (2011) menciona que o chá da raiz de $C$. jamacaru é utilizado para o tratamento de infecção urinária, problemas de coluna, reumatismo e em ferimentos. As informações obtidas em Lagoa e apresentadas na literatura apontam o significativo potencial medicinal dessa espécie, a qual deveria ser estudada a nível farmacológico para comprovar sua eficiência médica.

Estudos diversos apontam para o potencial medicinal de diversas espécies da família Cactaceae. Davet et al. (2009), registraram propriedades antibacterianas em C. jamacaru, inibidoras do crescimento de alguns microrganismos, devido a presença de esteróides. Agra et al. (2007) e Roque et al. (2010), em seus estudos no semiárido nordestino, registraram o uso de espécies do gênero Melocactus no tratamento de problemas respiratórios, tais como gripe e bronquite. Roque et al (2010) ainda registrou, no Rio Grande do Norte, o uso de $P$. gounellei no tratamento de inflamação da uretra.

Vale ressaltar que, em ambas as comunidades, C. jamacaru foi citada como bioindicadora de chuva, sendo essa espécie também registrada para tal finalidade em outros trabalhos como os de Lucena et al. (2005) e Albuquerque et al. (2010). A utilização de cactáceas para este mesmo fim também foi documentada na comunidade São Francisco do município de Cabaceiras, com destaque para a espécie P. pachycladus (LUCENA, 2011).

Pilosocereus gounellei foi mencionado nas comunidades estudadas como uma espécie que pode ser utilizada, em momentos de extrema necessidade, na alimentação humana, podendo ser consumido o fruto em fresco ou o miolo cozido. Contudo, Andrade et al. (2006a), em seu trabalho com os sertanejos baianos, registrou que o fruto é a parte menos utilizada de $P$. gounellei, devido ao seu sabor, sendo os frutos da palma e do mandacaru os preferidos para consumo entre eles. No uso como forragem, a espécie é servida ao gado depois que seus espinhos são queimados ou cortados. Outros estudos também registram semelhante prática, conforme, consta em Andrade et al. (2006a), Cavalcanti e Resende (2007) e Lucena (2011). Tanto em Barroquinha como em Besouro, o fruto em fresco também é consumido pelos pássaros na alimentação. Além da importância da espécie para outras categorias de uso, o espinho de $P$. gounellei também foi citado para uso tecnológico por uma informante, na confecção de rendas, em tempos passados, uso este ainda não registrado na literatura. 
"O espinho do xiquexique era usado como agulha para fazer renda de birro para almofadas"

(R. S. F., 56 anos).

Andrade et al. (2006a) registrou também a utilização do espinho do mandacaru como instrumento cirúrgico, sendo utilizado para costurar a genitália feminina de vacas após o parto.

\section{Valorização de espécies por homens e mulheres}

O conhecimento detido por homens e mulheres mostrou-se semelhante, em ambas as comunidades estudadas, como registrado em outros trabalhos (MATAVELE; HABIB, 2000; LUCENA, 2011). A espécie $C$. jamacaru recebeu o maior número de citação entre as outras plantas mencionadas, tanto entre homens quanto entre mulheres. Entretanto, essa espécie obteve maior número de citações entre mulheres, por ser usada mais frequentemente para finalidades medicinais, especialidade feminina. O predomínio das mulheres no conhecimento sobre espécies medicinais vem sendo apresentado na literatura etnobotânica, a qual também enfatiza que os homens são mais envolvidos com plantas usadas em construções e usos tecnológicos (LUOGA et al., 2000; TAITA, 2003; LAWRENCE et al., 2005; LUCENA et al., 2007). Este quadro pode ser explicado pelo fato de, geralmente, as mulheres serem as responsáveis pelo cuidado com a família. Em contrapartida, os homens ao realizarem trabalhos externos ao domínio residencial, no campo e/ ou áreas de vegetação, detêm maior conhecimento de plantas manufatureiras (LACUNA-RICHMAN, 2004). Contudo, essa dinâmica no conhecimento das espécies vegetais e suas utilizações podem mudar de região para região, e além mesmo entre comunidades da mesma região, como afirma Matavele e Habib (2000).

\section{Transmissão e manutenção do conhecimento local}

Nas comunidades estudadas, a transmissão do conhecimento ocorre predominantemente de forma vertical, por meio dos avôs e pais (70,4\%). Uma menor porcentagem de informantes $(0,8 \%)$ relatou ter adquirido o mesmo de forma circular, com os amigos ou vizinhos da comunidade (27,8\%). Entretanto, cerca de 50\% dos informantes relataram não transmitir o conhecimento que possui. Isso pode ser explicado pela desvalorização do conhecimento local sobre os recursos pelos moradores, bem como devido à ausência das plantas na área de estudo, conforme consta nos relatos abaixo:

"Antigamente o povo dava mais valor"

$$
\text { (E. D. P. S., } 42 \text { anos). }
$$

"Hoje não se usa mais porque dificilmente a

$$
\begin{aligned}
& \text { gente encontra" } \\
& \text { (L.S.F., } 33 \text { anos). }
\end{aligned}
$$

Situação semelhante foi encontrada por Lucena (2011), em uma comunidade do Cariri Paraibano, onde também se registrou o predomínio da transmissão de conhecimento através da forma vertical. No mesmo trabalho constatou-se ainda, à semelhança do presente estudo, elevada porcentagem de informantes que não transmitem o conhecimento, o que dificulta a perpetuação do mesmo entre os membros mais jovens da comunidade.

Os dados coletatos apontam que as potencialidades de uso das cactáceas nas comunidades Besouro e Barroquinha demonstram sua importância local. Os usos a elas atribuídos retratam a realidade cultural e socioeconômica das comunidades, uma vez que o conhecimento, hoje posto em prática, é fruto de experiências dos mais antigos em tempos de adversidade. Entretanto, atualmente, registra-se tendência ao esquecimento destes saberes. Deste modo, se faz necessário atentar para as causas destes acontecimentos, a fim de promover a preservação das cactáceas e do conhecimento local associado, bem como sua perpetuação entre as gerações futuras.

Sugere-se, ainda, a realização de estudos que testem o potencial médico dessas espécies, em virtude de sua ampla aplicação e diversidade no tratamento das enfermidades. 


\section{Referências}

AGRA, M. F.; BARACHO, G. S.; BASÍLIO, I. J. D.; NURIT, K.; COELHO, V. P.; BARBOSA, D. A. Sinopse da flora medicinal do cariri paraibano. Oecologia Brasiliensis, Rio de Janeiro, v. 11, n. 3, p. 323-330, 2007.

ALBUQUERQUE, U. P.; ANDRADE, L. H. C. Conhecimento botânico tradicional e conservação em uma área de Caatinga no Estado de Pernambuco, Nordeste do Brasil. Acta Botanica Brasilica, Feira de Santana, v. 16, p. 273-285, 2002.

ALBUQUERQUE, U. P.; LUCENA, R. F. P.; ALENCAR, N. L. Métodos e técnicas para a coleta de dados. In: ALBUQUERQUE, U. P.; LUCENA, R. F. P.; CUNHA, L. V. F. C. (Ed.). Métodos e técnicas na pesquisa etnobotânica. Recife: Editora NUPEEA, 2010. p. 40-64.

ALVES, J. J. A. Caatinga do Cariri Paraibano. Geonomos, Belo Horizonte, v. 17, n. 1, p. 19-25, 2009.

ANDRADE, C. T. S.; MARQUES, J. G. W.; ZAPPI, D. C. Utilização de cactáceas por sertanejos baianos. Tipos conexivos para definir categorias utilitárias. Sitientibus, Série Ciências Biológicas, Feira de Santana, v. 6 (Etnobiologia), p. 3-12, 2006 a.

ANDRADE, C. T. S.; MARQUES, J. G. W.; ZAPPI, D. C. Utilização medicinal de cactáceas por sertanejos baianos. Revista Brasileira de Plantas Medicinais, Botucatu, v. 8, n. 3, p. 36-42, 2006b.

APODACA, P. Cactus stones: symbolism and representation in Southern California and seri indigenous folk art and artifacts. Journal of California and Great Basin Anthropology, Orange, v. 23, n. 2, p. 215-228, 2001.

ARELLANO, E.; CASAS, A. Morphological variation and domestication of Escontria chiotilla (Cactaceae) under silvicultural management in the Tehuacán Valley, Central Mexico. Genetic Resources and Crop Evolution, Dordrecht, v. 50, n. 4, p. 439-453, 2003.

CARMONA, A.; CASAS, A. Management, phenotypic patterns and domestication of Polaskia chichipe (Cactaceae) in the Tehuacán Valley, Central Mexico. Journal of Arid Environments, Trelew, v. 60, p. 115-132, 2005.

CASAS, A.; CRUSE-SANDERS, J.; MORALES, E.; OTEROARNAIZ, A.; VALIENTE-BANUET, A. Maintenance of phenotypic and genotypic diversity in managed populations of Stenocereus stellatus (Cactaceae) by indigenous peoples in Central Mexico. Biodiversity Conservation, Madrid, v. 15, p. 879-898, 2006.

CAVALCANI, N. B.; RESENDE, G. M. Efeito de diferentes substratos no desenvolvimento de mandacaru (Cereus jamacaru P. DC.), facheiro (Pilosocereus pachycladus RITTER), xiquexique (Pilosocereus gounelli (A, WEBWR EX K. SCHUM.) BLY. EX ROWL.) e coroa-de-frade (Melocactus bahiensis BRITTON \& ROSE). Revista Caatinga, Mossoró, v. 20, n. 1, p. 28-35, 2007.

CAVALCANTI FILHO, J. R. C. A água como elo de identidades sociais no semi-árido paraibano: estudo de caso, Cabaceiras. 2010. 196 f. Dissertação (Mestrado em Desenvolvimento Regional e Meio Ambiente) - Centro Universitário de Araraquara, Araraquara. 2010.

CHAVES, T. P.; DANTAS, I. C.; FELISMINO, D. C.; DANTAS, V. S.; DANTAS, G. D. S. Lambedor: um conhecimento popular em abordagem científica. BioFar - Revista de Biologia Farmácia, Campina Grande, v. 2, n. 1., p. s/paginação, 2008.

CRUZ, M.; CASAS, A. Morphological variation and reproductive biology of Polaskia chende (Cactaceae) under domestication in Central Mexico. Journal of Arid Environments, Trelew, v. 51, p. 561-576, 2002.

DANTAS, I. C; GUIMARÃES, F. R. Plantas Medicinais Comercializadas no Município de Campina Grande, PB. Revista de Biologia e Farmácia. v. 1, n. 1, 2007.

DANTAS, V. S.; DANTAS, I. C.; CHAVES, T. P.; FELISMINO, D. C.; SILVA, H., DANTAS, G. D. S. Análise das garrafadas indicadas pelos raizeiros na cidade de campina grande PB. BioFar - Revista de Biologia Farmácia, Campina Grande, v. 3, n. 1, s/paginação, 2008.

DAVET, A.; VIRTUOSO, S.; DIAS, J. F. G.; MIGUEL, M. D.; OLIVEIRA, A. B.; MIGUEL, O. G. Atividade antibacteriana de Cereus jamacaru DC., Cactaceae. Revista Brasileira de Farmacognosia, Curitiba, v. 19, n. 2B, p. 561-564, 2009.

DUQUE, J. G. O Nordeste e as lavouras xerófilas. v. 193. 3. ed. Mossoró: Coleção Mossoroense, 1980. 265 p.

DUQUE, J. G. O Nordeste e as lavouras xerófilas. 4. ed. Fortaleza: Banco do Nordeste do Brasil, 2004. 88 p.

FERNÁNDEZ-ALONSO, J. L. Nueva especie colombiana de Browningia (Cactaceae, Cactoideae, Browningieae) potencialmente promisoria para el país. Revista de la Academia Colombiana de Ciências, Bogotá, v. 30, n. 114, p. 19-30, 2006.

FUENTES, V. R. Etnobotánica de Cactaceae em Cuba. In: GONZÁLEZ TORRES, L. R.; PALMADORA, A.; RODRÍGUEZ, A. (Ed.). Memorias del taller conservación de cactus Cubanos. La Habana: Jardim Botánico Nacional, Universidad de La Habana, 2005. p.15-24.

IBGE. Instituto Brasileiro de Geografia e Estatística. 2010. Disponível em: <http://www.ibge.gov.br/cidadesat/painel/painel. php?codmun=250810\#>. Acesso em: 4 ago. 2011.

JIMÉNEZ-SIERRA，C. L.; EGUIARTE, L. E. Candy Barrel Cactus (Echinocactus platyacantus Link \& Otto): A traditional plant resource in Mexico subject to uncontrolled extraction and browsing. Economic Botany, New York, v. 64, n. 2, p. 99-108, 2010.

LACUNA-RICHMAN, C. Subsistence strategies of an indigenous minority in the Philippines: nonwood forest product use by Tagbanua of Narra, Palawan. Economic Botany, New York, v. 58, p. 266-285, 2004.

LAWRENCE, A.; PHILLIPS, O. L.; REATEGUI, A.; LOPEZ, M.; ROSE, S., WOOD, D.; FARFAN, A. J. Local values for harvested forest plants in Madre de Dios, Peru: towards a more contextualised interpretation of quantitative ethnobotanical data. Biodiversity and Conservation, New York, v. 14, p. 45-79, 2005.

LIMA, J. L. Plantas forrageiras das caatingas: usos e potencialidades. Petrolina: EMBRAPA, 1996. 44 p.

LUCENA, C. M. Uso e diversidade de cactáceas em uma comunidade rural no Cariri Oriental da Paraíba (nordeste do Brasil). 2011. 53 f. Monografia (Graduação em Ciências Biológicas) - Universidade Federal da Paraíba, Areia. 2011.

LUCENA, R. F. P.; DE ARAÚJO, H. F. P.; MOURÃO, J. S.; ALBUQUERQUE, U. P. Aflor chegou, chuva avisou: meteorologia 
popular no semiárido paraibano. Atualidades em Etnobiologia e Etnoecologia. v. 2. Recife: Editora NUPEEA, 2005. 205 p.

LUCENA, R. F. P.; ARAÚJO, E. L.; ALBUQUERQUE, U. P. Does the local availability of woody Caatinga plants (Northeastern Brazil) explain their use value? Economic Botany, New York, v. 61, n. 4, p. 347-361, 2007.

LUNA-MORALES, C. DEL C.; AGUIRRE R. J. R. Classificación tradicional, aprovechamiento y distribución ecológica de la pitaya mixteca em México. Interciência, Caracas, v. 26, n.1, p. 18-24, 2001.

LUOGA, E. J.; WITKOWSKI, E. T. F.; BALKWILL, K. Differential utilization and ethnobotany of trees in Kitulanghalo Forest Reserve and surrounding communal lands, Eastern Tanzania. Economic Botany, New York, v. 54, p. 328-343, 2000.

MATAVELE, J.; HABIB, M. Ethnobotany in Cabo Delgado, Mozambique: use of medicinal plants. Environmental, Development and Sustainnability, London, v. 2, p. 227-234, 2000.

NILSEN, L. B.; DHILLION, S. S.; CAMARGO-RICALDE, S. L.; RENDÓN-AGUILAR, B.; HEUN, M. Tradicional knowledge and genetic diversity of Opuntia pilifera (Cactaceae) in the TehuacánCuicatlán Valley, Mexico. Economic Botany, New York, v. 59, n. 4, p. 366-376, 2005.
OLIVEIRA, F. C. S.; BARROS, R. F. M.; MOITA NETO, J. M. Plantas medicinais utilizadas em comunidades rurais de Oeiras, semiárido piauiense. Revista Brasileira de Plantas Medicinais, Botucatu, v. 12, n. 3, p. 282-301, 2010.

PEDROSA, T. M. Arte popular de Alagoas: pesquisa e organização. Maceió: Grafitex, 2000. 218 p.

PEREIRA, D. D. Mangas, malhadas e cercados: o semiárido que não se rende! Campina Grande: Impressos Adilson, 2009. 102 p.

ROQUE, A. A.; ROCHA, R. M.; LOIOLA, M. I. B. Uso e diversidade de plantas medicinais da Caatinga na comunidade rural de Laginhas, município de Caicó, Rio Grande do Norte (nordeste do Brasil). Revista Brasileira de Plantas Medicinais, Botucatu, v. 12, n. 1, p. 31-42, 2010.

TAITA, P. Use of woody plants by locals in Mare aux Hippopotames Biosphere reserve in western Burkina Faso. Biodiversity and Conservation, New York, v. 12, p. 1205-1217, 2003. 